\title{
A Brief History of Education in the United States: An Interview with Alan Singer
}

\section{Michael F. Shaughnessy, Greg Code}

Eastern New Mexico University, Portales, New Mexico

\section{Abstract}

In this interview, Alan Singer provides a comprehensive review of the field of American education. He discusses it's beginnings and current concerns. He responds to questions about school reform and educational issues.

Submitted

24 December 2015

Revised

09 January 2016

Accepted

08 February 2016

Keywords:

American Education

pedagogy

curriculum

\section{Suggested Citation:}

Shaughnessy, Michael F., Code, Greg (2015). A Brief History of Education in the United States: An Interview with Alan Singer, International Journal of Academic Research in Education, 1(2), 64-74. DOI: $10.17985 /$ ijare.404886

\footnotetext{
${ }^{1}$ Michael.Shaughnessy@enmu.edu Gregory.Code@enmu.edu
} 


\section{INTRODUCTION}

All too often, other nations turn to the United States as a model of education, educational policy and theory. In order to understand the present history of the United States educational system, it is imperative to study the past. Alan Singer, in this interview, presents an overview of the educational system in America and comments on its history. It is hoped that this interview will shed some light on the intricacies and complexities of the American educational system and provide an overview of its history.

In the past, the United States was a model of mass democratic education, educational policy, and theory around the world, especially education as a vehicle for technological innovation, the assimilation of diverse immigrants into a united citizenry, and for social mobility. American global economic and military ascendency after World War II was accompanied by respect for and replication of its educational system.

However, at the end of the 20th century, as the U.S. economic engine appeared to stall, as social inequality stubbornly continued in the country, as the wealth gap increased, as new economic and technological centers developed in East Asia, and as new challenges to American cultural dominance emerged, the United States began questioning whether its educational system was adequately preparing youth for 21st century careers.

In order to understand the present history of the United States educational system, it is imperative to study the past. Dr. Alan Singer has a doctorate in history from Rutgers University, is a retired New York City high school social studies teacher, and is a teacher educator at Hofstra University in Hempstead, New York.

He has written and spoken widely on the school-to-prison pipeline, the negative impact of Common Core standards and high-stakes standardized tests on curriculum and teaching, and the consequences of the privatization of education and the de-professionalism of teaching.

In this interview, he presents an overview of the educational system in the United States and comments on education history. It is hoped that this interview will shed some light on the intricacies and complexities of the American educational system.

1) What interests you most about the history of education in the United States?

I am a historian, a teacher, and a long-term political activist committed to social justice, which is the latest code term describing what Fox Bill O'Reilly calls "loony liberals." I was attacked on right-wing websites as a "social predator" after I wrote an article for the journal Rethinking Schools on ways social studies teachers can encourage active citizenship by involving students in political action projects. I actually liked being identified as a social predator and designed a tee-shirt to wear at conferences modifying the logo of the Nashville Predator hockey team. I am also a parent and grandparent. All of these "identities" factor into my interest in the history of education in the United States.

A class on the history of education was a requirement in the teacher certification program I completed as an undergraduate student in the 1960s. It was not a very interesting class, almost all lecture with no room for discussion, and was taught by a largely disinterested teacher. I once asked him in front of the class why the information he was regurgitating for us was important to know. He looked at me blankly and responding something to the affect "if teachers don't know it, who will." At that point I swore to myself I would never take another teacher education class, which is somewhat ironic because I now teach them.

Because I earned New York State teacher certification through an undergraduate teacher education program, I was free to study history in my masters and doctoral programs. As a sixties activist, I was especially interested in the emergence of class-consciousness in radical working-class political 
movements. Later, when I became a high school social studies teacher, my interest broadened to trying to understand transformative thinking that motivated people in all walks of life to change the way they view the world and their position in it and to become agents for progressive and liberatory social change. I guess this was my backdoor entry into study of the history of education in the United States, the role education has played in shaping the nation, the role political debates play in shaping education, and the possibility of engaging young people as politically active citizens and transformative agents for building a more just society.

In the United States education has often be seen as a force for social change, social mobility, and broader democratization. My alternative take rooted in the work of Italian thinker Antonio Gramsci and Brazilian educator Paulo Freire is that formal education in the United States has generally been a force for replicating a hierarchical society and all its inconsistencies and injustices. However, inconsistencies do create space for more democratic approaches to learning and for teachers to encourage active citizenship and political activism.

2) When you say "broader society," who exactly are you talking about?

In a series I wrote for Huffington Post on the history of education, I discussed the relationship between educational reform proposals and debates going on in the broader society. The Puritans started quasipublic schools in colonial Massachusetts because they feared the influence of Satan, the "Old Deluder," on their youth. Reformers like Horace Mann in the 19th century were concerned about the Americanization of newly arrived immigrants. Indian boarding schools and 20th century high schools were established, at least partly, to assimilate groups seen as resisting the mainstream culture or potentially subversive during times of war. In each of these cases, schools were seen as instruments for enforcing political mandates demanded by ruling groups.

3) What do you feel is the biggest basic debate in the "broader society", currently?

I think that the biggest debate in the broader society is over the nature of the United States itself and education and schools are just part of this broader debate. The United States census just released updated projections that around 2050 non-Hispanic "Whites" will no longer be a majority of the population in this country. Non-Hispanic Whites children are probably already no longer a majority of students in public schools. There are groups who feel displaced by this demographic shift and that it is no longer, or will no longer, be "their" country. I think this is behind demands we heard in the Republican Party Presidential debates for surrounding the United States with high walls. The debate takes many forms.

There are religious components with concern that the United States will no longer be a Christian nation, although constitutionally it never was. There is also a deep economic malaise as globalization and what Pope Francis called unbridled capitalism have increased the gap between rich and poor and more and more people who defined themselves as middle class find themselves in debt and marginalized.

So far, the political right has had success demonizing labor unions, social service programs, teachers, health insurance, pensions, and public schools, blaming them for all-that-ails-us, and demanding privatization. Public schools and teachers have caught the brunt of the attack with demands for scripted curriculum, high-stakes testing, evaluating teachers, and the abandonment of tenure protection, but I do not think the debate is primarily about schools. 
4) Why isn't the United States' world ranking in public education a basic debate in the "broader society"?

The basic reason is that for all their assaults on teachers and public schools, the so-called "reformers," I call them deformers, who are pushing for vouchers, privatization, tax credits, and charter schools, who know how to make money at the expense of children and families, have no clue about what to do to improve schools, especially in inner-city minority communities. They do not want to address inequality, discrimination, unemployment, and substandard housing. They want a cheap fix that will profit them. Maybe in the end they will just build their walls around the inner cities too.

Even more hopeful goals, such as President Obama's call to prepare all children for 21st century colleges and careers, have major problems. Obama and his group of reformers have no idea what 21st century careers will look like. They are big at pushing technology jobs, but if schools train every high school kid to be a computer coder, soon there will be an enormous over-supply. Americans already cannot compete economically with lower paid Asian coders who just email in their work.

5) Why do you think many of the early teachers were female when boys were originally the only ones attending school?

Interesting question. We are looking at a rural agricultural society where men were expected to do manual labor, either on farms, or in skilled support trades like smithing, carriage making, or leather work. Boys were needed on the farm or as apprentices and anything more than minimum literacy was seen as a waste of muscle power. In the late 19th and early 20th century teaching was overwhelmingly a woman's job.

Women's work was not valued, and either was the work of teachers. Female teachers were seen as transients holding jobs until they married. However many school districts refused to hire, fired, or discriminated against married women teachers until the World War II labor shortage. It was not until 1974 that the Supreme Court ruled that pregnant teachers could not be forced to take maternity leave against their will. The perception that teaching was women's work is a major reason teacher salaries trailed those of other professionals.

6) Why do you think the shift out of religion as a reason for education occurred?

Most of the original British colonists in what would become the United States were Protestant and their sects believed members had to be able to read and interpret the Bible. This was a major reason for the early establishment of schools in Massachusetts. I think three forces led to at least the partial separation of church and school. The large number of competing Protestant sects is one reason for the doctrine of separation of church and state in this country. Each religious group feared they could be taxed to support a powerful competing church much as was done throughout most of Europe.

The second powerful force was the Industrial Revolution which shifted population from rural areas to cities and made the nation much more secular. I think the third factor was the push to assimilate immigrants. Both Catholics and Jews resisted having their children attend schools they perceived of as Protestant efforts to convert them. But remember, it was not until the 1960s that the Supreme Court ruled against Bible reading and school lead prayers.

7) We've had flows of documented and undocumented immigrants since the inception of the public school system. Why do you think this is a continuing debate in educational reform?

At the same time as communities resist funding education and paying teachers competitive salaries they expect schools to perform miracles. One miracle is the rapid assimilation of immigrants. New immigrant groups, the Irish in the 1840s, Jews and Southern Italians from 1880 to 1920, and Latinos and East Asians 
today, have been seen as either a threat or as simply outside the norm. Change makes a lot of people uneasy because they fear being left behind, change from rural to urban, from agricultural to industrial, and now change from industrial to technological.

The debate over educating immigrant children is just a continuation of the debate over immigration and the broader debate over the nature of American society. Immigrants are easy targets because they speak other languages, wear different clothing, and follow different cultural practices. They become the target of groups that feel disposed.

8) Why do you think it took so long to get teachers educated/competent to the extent they are today?

The first two-year normal or teaching schools were started in the United States in 1823, but in many parts of the country teaching did not require a four- year college degree until after World War II. Historian Robert Hofstadter argued that there is a long history of anti-intellectualism in American society. There has also been a history of right-wing hostility to unionization and to paying taxes to support social services like education. Everybody wanted professional teachers, but no one wanted to pay for them or pay them.

Even today, states like New York want individuals to complete stringent certification requirements and pay up to a thousand dollars for certification exams, because even if it does not ensure quality teachers, it is much cheaper than tax payers supporting ongoing teacher develop.

9) Did teachers unions have any impact on the schools in America?

I have not always agreed with the leadership of the teachers' union in the United States but I am a big supporter. Without teacher unions salaries were unprofessional and school districts freely discriminated against women, minorities, and political dissidents. In New York City high schools were I worked in the 1970s and 1980s, the only thing that held down class size was the teachers contract. Without tenure teachers would be afraid to question administrators and curriculum. We tell students to become active citizens in a democratic society but teachers were threatened with losing jobs if they speak up or held contrarian beliefs. Tenure is not a guarantee of lifetime employment but of due process. In most states it is illegal for teachers as public employees to go on strike. Not only has this weakened teachers, but it has weakened families and students because many of the most able teachers move on for higher salaries, job protection, satisfaction, and respect.

10) Could you comment on the use of corporal punishment in the schools in America?

Corporal punishment has been around a long time. In 1847, Walt Whitman wrote an editorial for the Brooklyn Eagle complaining of "military discipline," the demand for "slavish obedience" in schools, and the use "whipping sticks" and the "flogging system." Conservatives wax poetic on how wonderful things used to be including schools when corporal punishment was permitted. The reality is that corporal punishment never worked, unless the goal was to force people out of school. In the 19th century "bad" boys, those usually subjected to corporal punishment, quit school and went to work on farms. In the first half of the 20th century they dropped out and took manual labor jobs. Since World War II, the same group of school phobic boys has been forced to remain in school longer because there is no outside work for them. New Jersey was the first state to prohibit corporal punishment in schools in 1867.

Currently, corporal punishment is banned in public schools in 31 states and the District of Columbia, which means it is still permitted in19 states. It is supposedly widely used in some Southern religious schools. But demeaning and unfair punishment is still with us only with a different name - zero tolerance. 
Zero tolerance disciplinary policies transform minor transgressions of school rules from educational opportunities into disciplinary matters where students are subject to suspension and involvement with police and courts. Zero-tolerance policies were implemented in schools despite research showing they were detrimental to student emotional and academic growth and reproduced the types of behavior they were intended to prevent. The push for zero-tolerance policies in schools and society was feed by media generated frenzy and racism and has disproportionately affected African American and Latino youth.

11) Would you consider yourself a historian of education in the United States? In your mind, who are the stellar historians of education, and why do we need to have a comprehensive understanding of the history of education?

I did a presentation on slavery in New York at a local high school. After I spoke, a young African American woman thanked me for teaching the history of Black people. I thanked her for coming up to me, but said I consider myself an American historian, and looked at Black history because it was integral to understanding the history of the United States.

I say the same thing about the history of education! It is a focal lens for examining American history and society that includes racism, class hierarchy, immigration, industrialization, and now globalization. Three historians worth noting who focus on the history of education in the United States are Lawrence Cremin, Joel Spring, and Diane Ravitch.

While I do not agree with everything they report, each tries to imbed the history of education in the larger debates taking place in American society. In addition, Dana Goldstein has written a new history of teaching called The Teacher Wars. Blackboard Unions by Marjorie Murphy is an excellent history of teacher unions in the 20th century. Lois Weiner has also written extensively and powerfully on education in books and articles that always reflect the history of struggles.

Questions for Alan Singer: A Brief History of Education in the United States -Part II

\section{1) What is your opinion on the Common Core Standards?}

If you can put aside the high-stakes testing, which admittedly is not easy to do, and if you put aside the break-up of learning into micro-pieces, which I really cannot forgive, and if you can somehow forget the push for corporate take over and profit from education in the United States, there are some are some decent curriculum ideas imbedded in the national Common Core English Language standards. Unfortunately, even the better ideas, reading carefully, looking for underlying meaning in a passage, editing writing, and supporting arguments with evidence, are often laid-out and taught in ways that just do not make academic sense. For example, it would be great if history and English were aligned so students could read and write about primary source documents in their English classes while learning about historical forces and social movements in social studies. But the 11th grade ELA curriculum in New York State for September and October starts with the question "How have immigrants shaped the culture and land of the United States"?

It is a great question, but in social studies classes students will not get to the 1840-1880 wave of immigration until November at the earliest and probably will not study about Eastern and Southern European immigrants in an industrializing and urbanizing America until January. Contemporary immigration and current debates won't be touched until May or June. Meanwhile, in ELA classes, students do not read the founding documents including the Declaration of Independence and the United States Constitution until November and December when social studies classes are already into the Civil War and starting on industrialization. Again the ELA curriculum has a great organizing question, "How did the founders of the United States balance protecting individual rights and creating a strong union in the nation's founding documents?" 
But it is not aligned with the social studies curriculum where it would support actual student learning.

The reason for this mishmash is that Common Core completely disengages academic skills from content understanding, a fundamental flaw that cannot be easily corrected. The Common Core approach to reading is like breaking a molecule down into individual elements. But as any science teacher can explain, once you break the molecular bonds that tie the atoms together, you lose all the properties of the original chemical. You now have hydrogen and oxygen, but you no longer have water. In Common Core, students may learn skills, but they do not learn to love reading or to really understand sophisticated written material.

2) How did the Zero tolerance policies come into existence and who thought this was a solution to the problem at hand?

Zero-tolerance policies grew out of White fears of inner-city Black crime in the 1980s and were fed by media frenzy. They started to be routinely enforced in public schools after federal legislation, the GunFree Schools Act (1994), required states to expel students who brought a firearm to school or face losing federal funds. Zero tolerance for possession of any type of potential or imagined weapon and drugs, including prescription or over-the-counter medications, as well as a range of misbehaviors, soon became grounds for severe disciplinary action including expulsion.

A 1999 article in USA Today estimated that 87\% of all schools in the United States had instituted zerotolerance policies for drug possession and $91 \%$ for weapons. But according to the article, implementation of zero-tolerance policies varied widely from school-to-school and district-to-district. Additionally, zerotolerance policies were often employed inexplicably. Students were suspended or expelled from school for possessing "Midol, Tylenol, Alka Seltzer, cough drops and Scope mouthwash" - and for wearing "Halloween costumes that included paper swords and fake spiked knuckles, as well as for possessing rubber bands, slingshots and toy guns - all violations of anti-weapons policies." These policies were implemented in schools despite research showing that resultant suspensions were detrimental to both a student's emotional and academic growth.

According to a 2006 study sponsored by the American Psychological Association, school violence was not on the rise when the zero tolerance policies were implemented, discipline and suspension rates varied widely nationwide, suspension rates increased primarily because of the time schools spent on disciplinary matters; and suspension rates negatively affected academic achievement. One early study found that suspensions resulting from zero tolerance policies actually reinforced student behaviors they were supposed to eliminate leading to further suspensions. Another study found that when suspended from school male teenagers were increasingly exposed to influences that virtually ensured further problems in schools and with the police. Other studies have documented the connection between zero tolerance policies and higher school drop out rates.

In New York City, between 1998 and 2007 the number of zero tolerance infractions rose from seven to twenty-nine. This resulted in the doubling of suspensions between 2002 and 2008. In 2008-2009 almost 75,000 New York City students were suspended compared to a approximately 43,000 in 1999-2000, an increase of almost 60\%. Under pressure to reduce school suspensions, the number of suspendable infractions was reduced to twenty-one in 2011, which was still three times the 1998 number. A longitudinal study of suspensions in New York City schools from 2005 to 2008 found that rather than being disciplinary correctives, they correlated with increased rates of absenteeism and lateness, lower passing rates in classes and on standardized examinations, and decreased graduation rates. 
3) Do you feel the increased integration of computers and new instructional technology into the classroom is the right direction for our educational system?

My students can't decide if I am a technological dinosaur or a Luddite bent on smashing the machine. I have always been a bit of a skeptic about the value of technology in the classroom, I call myself a "technosaurus" or technical dinosaur, although a number of the best teachers I work with rank as advanced techno-geeks. Technology cannot substitute for good teaching and it is destructive if it interferes with student-teacher and student-student relationships. But the reality is that it can be used judiciously and wisely. There was a sportscaster in the 1970s who popularized the phrase "Let's go to the videotape!" to document stories. In class I like to go to the Internet to help students find answers to their questions and to illustrate key points. By the way, the technosaurus was actually a real dinosaur.

It was about three feet long, weighed in at twenty pounds, and lived over 200 million years ago. Its remains were discovered near Texas Tech University, hence its name. The university is lobbying to have the technosaurus declared the official dinosaur of the State of Texas.

4) Why do you think there is a growing resistance from both teacher organizations and parent groups regarding high-stakes testing and data tracking of student and teacher performance?

Opt-Out is a parent-led campaign supported by many teachers against Common Core aligned high-stakes tests used to evaluate students, teachers, and schools. In 2015 it moved from the political margins and emerged as a full-scale social movement committed to the idea that education should be about children, not testing. States have not yet abandoned Common Core and Race to the Top mandated high-stakes testing, but as the Opt-Out movement continues to grow and its pace of growth continues to accelerate, I believe they will. This spring more than 200,000 children in grades 3 to 8 in New York State alone opted out of either the English or math tests or both. It was about $20 \%$ of the potential test takers in the state. It was a major success for parents in the Opt-Out movement opposed to constant testing and test driven curriculum.

The State Education Department acknowledged that the high opt-out rate has interfered with its ability to use test results to evaluate students, teachers, and schools. Much of the opposition to the testing regime arose because it transforms schools into test prep academies. According to NYS Allies for Public Education spokesperson Jeanette Deutermann "Opting out the week before the test, the teacher still test preps throughout the year. From the first day of school, we want teachers to know the test has no bearing on them."

5) Do you think high-stakes testing and data tracking of student and teacher performance is a good thing? Why or why not?

Curriculum needs to define assessment, but in the age of high-stakes testing priorities are reversed testing determines curriculum. The curriculum is not what is important to know and makes us better human beings. It is what is easiest to test. When teachers know they are being evaluated based on student scores on these tests and their jobs are on the line, it transforms schools into test prep academies.

Pearson, one of the major testing companies, maintains mass Common Core grading centers where a college degree but no special knowledge is required to grade tests and temporary employees make between $\$ 12$ and $\$ 14$ an hour plus small bonuses if they hit daily quality and volume targets. Pearson insists strict training and scoring protocols are intended to ensure consistency, no matter who is marking the tests." 
Bob Sanders, vice president of content and scoring management at Pearson North America compared the scoring of high-stakes standardized Common Core-aligned exams at these mass scoring centers to making hamburgers at McDonald's. "McDonald's has a process in place to make sure they put two patties on that Big Mac. We do that exact same thing. We have processes to oversee our processes, and to make sure they are being followed." Mr. Sanders, of course, has a degree from the University of lowa in business and has never been a teacher. According to his Linkedin page, he considers himself a "A respected dynamic leader, strategic thinker, and creative problem solver within technology, retail, and the educational assessment industries." Probably why he thinks children should be processed like hamburgers.

6) Over the past 30-40 years we have seen an increase in the number of students with exceptionalities, handicaps, disabilities, special needs - whatever politically correct term you want to use - but how has it impacted the teacher's ability to deliver instruction?

I think you mean politically appropriate or sensitive. My understanding is that the movement has been to find ways to support the social and intellectual development of all children while recognizing both that everyone does not have the same potential and that we do not know in advance know what that potential is. Schools cannot solve every societal problem and they certainly cannot do what they do cheaply.

Children with special needs require more support and more structured learning environments. In New York City there are thousands of former classroom teachers now assigned to a surplus teacher pool. I do not see why they are not used as push in teachers assisting in classrooms and working with students either classified or unclassified who need additional support. In affluent suburban communities children with special learning needs seem to always get this type of support and it enhances the ability of teachers to deliver on instruction.

7) Teacher training - is there too much theory and not enough practice - or too much book learning and not enough hands on experiences?

As a teacher educator, I am very hands-on and experiential. I like to make the point that I am a retired high school teacher as well as a teacher educator. I teach general and social studies methods classes and then I observe students replicating and further developing the lessons in secondary school classrooms. I also teach demonstration lessons in secondary schools so my teacher education students can see me teach. There needs to be a blend of both theory and practice. The pendulum swings back and forth. Teachers do not need to be experts in theory and research, but they should insist that curriculum, pedagogy, assessments and all the latest innovations be based on sound theories and research about how students learn. That is one of the big problems with Common Core and the Common Core aligned assessments. It is a closed system. The tests test the Core, but I do not think either reflects sound learning and assessment practices.

8) It seems that our ability to test/evaluate assess students has outgrown our ability to remediate. Do you see this as a concern or am I the only one who sees this paradox?

In the United States, we pretend that everyone has the same opportunity and that failure to achieve is somehow the fault of an individual's culture or lack of will. It makes it easy to blame individuals and groups for social inequality and an increasingly rigid class system when the reality is we live in a hierarchical society that continually sorts people out and offers some individuals and groups decided advantages. The test/assess mess is used to justify this system. 
Remediation is a way of claiming you had an extra chance and blew it. Remediation is expensive, it often does not work because some people do have real limitations, and it certainly will not address deeply rooted social problems like racism, structural unemployment, globalization, unequal school funding, and ghettoization.

9) Grade retention and social promotion - is it still an issue in the year 2015?

Do we really want twenty-year olds sitting in third grade classrooms because they did not score high enough on the Common Core tests? This is not about social promotion but what makes sense for students who are having difficulty and for the other students in a class and school. Other advanced industrial countries have alternative tracks that allow young people to receive specialized training in different areas where they have some aptitude. In Cuba, every high school graduate is ensured a job if they stick with it, but they do not require that they pass a Common Core aligned test to enter job heaven.

The United States pretends in the Race to the Top No Child is Left Behind and everyone succeeds. But this is just pretend. And even if you win the Race to the Top, you can end up structurally unemployed when your job if shipped overseas where workers are paid a fraction of what they would earn in the United States. A spoon full of sugar helps the medicine go down, but we need some real medicine to fix this system.

10) What have we neglected to ask?

In Social Studies for Secondary Schools I wrote about historians who have shaped my own thinking about the past and present. I strongly recommend teachers read E. H. Carr's short book, really an extended essay, What is History? Carr introduced me to the idea of thinking about the past and present as part of a continuum that stretches into the future. He believes that concern with the future is what really motivates the study of the past. I strongly agree with Carr. Our concern for the future of education in the United States requires that we understand forces from the past that created the present.

\section{Conclusion}

In this brief series of interviews, Alan Singer has shed some light on some of the perennial issues facing education, educators and the learning process. The purpose of this interview was to examine and explore some of the main critical, crucial issues in the history of education.

Education in the United States cannot be discussed without examining historical currents and contemporary issues. It seems education has somehow always been expected to address the major questions or crises of the day whether it was declining religious orthodoxy in Puritan New England, the need to assimilate different waves of immigrants and prepare them for the workforce, or to promote patriotism during World War I and II and after September 11, 2001. Today's educational debates center on the most effective ways of adapting to technological changes, ensuring a measure or racial, ethnic, and gender equity, and preparing youth for new work demands. But they also involve the role of private groups in shaping educational policy, disagreements about what should be taught and how, the efficacy of high-stakes testing, and challenges to teachers as professionals.

In this question and answer series, Dr. Alan Singer has shed some light on some of the perennial issues facing education, educators and the learning process. The purpose of this interview was to examine and explore some of the main critical, crucial issues in the history of education. Granted, there are other realms to be explored - such as the philosophy of education, and the funding of education, but these questions and responses have focused on key issues in American education- past, present and future. 
References

Singer, A. (2014) Education Flashpoints: Fighting for America's Schools .New York: Routledge

Singer, A. (2011) Teaching Global History, A Social Studies Approach. New York: Routledge,

Singer, A. (2013) Teaching to Learn, Learning to Teach: A Handbook for Secondary School Teachers, 2nd edition. New York: Routledge,

Singer, A. (2014) Social Studies For Secondary Schools, 4th Edition New York: Routledge,

Singer, A. (2008) New York and Slavery, Time to Teach the Truth Albany, NY: SUNY Press, 